\title{
PARTICULARITĂŢILE IHTIOFAUNEI DIN ZONA DE CONFLUENȚĂ A RÂULUI RĂUT CU FLUVIUL NISTRU ÎN PERIOADA REPRODUCTIVĂ
}

\section{Bulat Dumitru, Bulat Denis, Usatîi Marin, Fulga Nina, Crepis Oleg, Șaptefraţi Nicolae, Chelmenciuc Rostislav}

Institutul de Zoologie al A.Ș.M. Chișinău, str. Academiei 1, MD-2028, E-maiI:bulat.denis@gmail.com, bulat.dm@yahoo.com https://doi.org/10.53937/9789975315975.73

Summary: At present, particular attention is paid to large rivers without realizing that the ecological status of a large lotic ecosystem depends on the state of its tributaries. Thus, in the conditions of growing anthropogenic presetting, we aimed to demonstrate the importance of the ecotone zones formed between two riparian ecosystems of different sizes, in order to ensure the welfare of the fish resources on both sides.

\section{Key words:}

\section{INTRODUCERE}

În prezent, condiţiile ecologice deplorabile în care se află râurile mici din Republica Moldova au provocat modificări radicale atât la nivel structural, cât și funcţional $[1,2,6]$. Impactul major asupra ecosistemelor râurilor mici poate fi dedus chiar însăși din funcţiile îndeplinite de ele. În timp ce ele ar trebui să participe la procesele de autoepurare a apei, în prezent servesc ca loc de stocare a deșeurilor și sursă suplimentară de poluare a râurilor mari în care debușează.

Această problemă a devenit și mai stringentă la aplicarea unor factori de decizie, când starea ecologică a unui râu este apreciată ca media rezultatelor colectărilor de probe din diferite sectoare. De aceea, când afirmăm că ecosistemul râului Răut conţine 43 specii de pești, remarcăm în aparenţă o bogăţie specifică semnificativă, dar în esenţă este departe de realitate, avându-se în vedere, că sectorul superior practic în totalitate a secat ca rezultat al fragmentărilor, iar cel inferior își datorează diversitatea specifică fluviului Nistru în care debușează.

Printre factorii negativi care erodează semnificativ diversitatea ihtiofa- 
unistică din r. Răut, pe lângă fragmentările multiple de albie constatate în sectorul superior și mijlociu (ce duc în unele perioade la secarea totală a albiei), se poate menţiona: deversările sistematice de poluanţi în zonele urbane (mun. Bălţi, or. Florești și or. Orhei) și rurale (satele din preajmă), regularizarea șenalului de curgere pe distanţe mari, instalarea gardurilor ilicite pentru concentrarea peștilor, braconajul incontrolabil la gurile râului cu plase și curent electric, ș.a. [1].

Astfel, în condiţiile presingului antropic crescând, ne-am pus ca scop să demonstrăm cât de importante sunt zonele de ecoton formate între două ecosisteme riverane de dimensiuni diferite în vederea asigurării bunăstării resurselor piscicole de ambele părţi.

\section{MATERIALE ȘI METODE}

Prelevările de material ihtiologic s-a efectuat în ecosistemul r. Răut pe parcursul anilor 2004-2018 cu ajutorul năvodului pentru puiet ( $=5$ m și dimensiunile laturii ochiului $\varnothing 5 \mathrm{~mm}$ ). Majoritatea indivizilor capturaţi au fost reîntorși în apă în stare vie. Pentru studiul de laborator o parte neînsemnată s-a fixat în soluţie de formol de $4 \%$. Analiza materialului ihtiologic s-a efectuat prin utilizarea metodelor clasice ecologice și ihtiologice $[3,4,5,7]$. Datele obţinute au fost prelucrate statistic, utilizând programele Excel - 2007. Valorile indicilor ecologici analitici și sintetici exprimă următoarele semnificaţii:

D1 Subrecedente: $<1,1 \%$
D2 Recedente: 1,1\%-2\%
C1 Accidentale: $<25 \%$
W1 Accidentale: $<0,1 \%$
D3 Subdominante: $2,1 \%-5 \%$
C2 Accesorii:25,1\%-50\%
W2-W3 Accesorii:0,1\%-5\%
D4 Dominante: 5,1\%-10\%
C3 Constante: $50,1 \%-75 \%$
W4-W5 Caracteristice:5,1\%-100\%
D5 Eudominante: >10\%
C4 Euconstante:75,1\%-100\%

\section{REZULTATE ȘI DISCUŢII}

Inventarierea ihtiofaunei r. Răut în anii 2004-2018 a pus în evidenţă 43 taxoni aparţinând la 10 familii: Esocidae (1 sp.), Cyprinidae (23 sp.), Ne- 
macheilidae (1 sp.) Cobitidae (2 taxoni), Siluridae (1 sp.), Gasterosteidae (2 sp.), Sygnathidae (1 sp.), Percidae (5 sp.), Gobiidae (6 sp.), Centrarchidae (1 sp.) (Tabelul 1) [1, 2].

Această diversitate ihtiofaunistică semnificativă, la prima vedere, pe care o găzduiește ecosistemul r. Răut, este constituită din două elemente de bază:

1. Specii caracteristice unui râu mic. Majoritatea taxonilor fac parte din grupa celor euritope cu ciclul vital scurt (obleţul, boarţa, murgoiul-bălţat, carasul argintiu, bibanul, babușca, speciile de zvârlugi, ciobănașul, mocănașul, osarul, ș.a).

2. Specii caracteristice fl. Nistru, dar care în anumite perioade intră activ în afluenţii săi. O pondere semnificativă de taxoni prezintă o valoare economică majoră (plătica, șalăul, avatul, scobarul, somnul, cleanul, morunașul, crapul, sângerul, ocheana, mreana comună, ș.a.).

Tabelul 1. Dinamica diversităţii ihtiofaunistice în r. Răut, în aspect succesional

\begin{tabular}{|c|c|c|c|c|c|}
\hline \multirow[b]{2}{*}{ No } & \multirow[b]{2}{*}{ Specia } & \multicolumn{3}{|c|}{ r. Răut } & \multirow[b]{2}{*}{ Zona caracteristică } \\
\hline & & 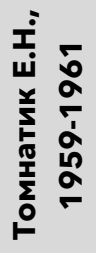 & 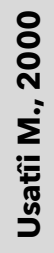 & 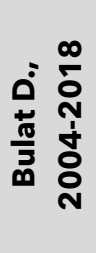 & \\
\hline 1 & Esox lucius Linnaeus, 1758 & + & + & + & Confluenţă/Albie \\
\hline 2 & Cyprinus carpio Linnaeus, 1758 & + & + & + & Confluență/ Albie \\
\hline 3 & Carassius carassius (Linnaeus, 1758) & + & + & - & Confluenţă/Albie \\
\hline 4 & Carassius gibelio (Bloch, 1782) & + & + & + & Confluenţă/Albie \\
\hline 5 & Barbus barbus (Linnaeus, 1758) & - & + & + & Confluenţă \\
\hline 6 & Gobio sarmaticus Berg, 1949 & + & + & + & Albie \\
\hline 7 & $\begin{array}{l}\text { Romanogobio kessleri (Dybowski, } \\
\text { 1862) }\end{array}$ & - & - & + & Confluenţă \\
\hline 8 & $\begin{array}{l}\text { Pseudorasbora parva (Temminck \& Sc- } \\
\text { hlegel, 1846) }\end{array}$ & - & + & + & Albie \\
\hline 9 & Abramis brama (Linnaeus, 1758) & - & + & + & Confluenţă \\
\hline 10 & Ballerus sapa (Pallas, 1814) & - & - & + & Confluenţă \\
\hline 11 & Blicca bjoerkna (Linnaeus, 1758) & - & + & + & Confluenţă \\
\hline 12 & Vimba vimba (Linnaeus, 1758) & - & - & + & Confluenţă \\
\hline
\end{tabular}




\begin{tabular}{|c|c|c|c|c|c|}
\hline 13 & Rutilus rutilus (Linnaeus, 1758) & + & + & + & Confluenţă/Albie \\
\hline 14 & Rutilus heckelii (Nordmann, 1840) & - & + & + & Confluenţă \\
\hline 15 & Rutilus frisii (Nordmann,1840) & - & + & - & Confluenţă \\
\hline 16 & Rhodeus amarus (Bloch, 1782) & + & + & + & Confluenţă/Albie \\
\hline 17 & Chondrostoma nasus (Linnaeus, 1758) & - & + & + & Confluenţă \\
\hline 18 & Aspius aspius (Linnaeus, 1758) & + & + & + & Confluenţă \\
\hline 19 & Squalius cephalus (Linnaeus, 1758) & + & + & + & Confluenţă/Albie \\
\hline 20 & Leuciscus leuciscus (Linnaeus, 1758) & + & + & + & Confluenţă/Albie \\
\hline 21 & $\begin{array}{l}\text { Scardinius erythrophthalmus (Lin- } \\
\text { naeus, 1758) }\end{array}$ & + & + & + & Confluenţă/Albie \\
\hline 22 & $\begin{array}{l}\text { Hypophthalmichthys molitrix (Valenci- } \\
\text { ennes, 1844) }\end{array}$ & - & + & + & Confluenţă \\
\hline 23 & $\begin{array}{l}\text { Hypophthalmichthys nobilis (Richar- } \\
\text { dson, 1845) }\end{array}$ & - & + & + & Confluenţă \\
\hline 24 & $\begin{array}{l}\text { Ctenopharyngodon idella (Valencien- } \\
\text { nes, 1844) }\end{array}$ & - & + & + & Confluenţă \\
\hline 25 & Leucaspius delineatus (Heckel,1843) & + & + & + & Confluenţ̧ă \\
\hline 26 & Alburnus alburnus (Linnaeus, 1758) & + & + & + & Confluenţă/Albie \\
\hline 27 & Barbatula barbatula(Linnaeus, 1758) & + & + & + & Albie \\
\hline 28 & Misgurnus fossilis (Linnaeus, 1758) & + & + & + & Albie \\
\hline 29 & Cobitis sp. & + & + & + & Confluență/Albie \\
\hline 30 & Silurus glanis Linnaeus, 1758 & - & + & + & Confluenţă \\
\hline 31 & Pungitius platygaster (Kessler,1859) & + & + & + & Confluenţă/Albie \\
\hline 32 & Gasterosteus aculeatus Linnaeus, 1758 & - & - & + & Confluenţă/Albie \\
\hline 33 & Syngnathus abaster Risso, 1827 & - & - & + & Confluenţă/Albie \\
\hline 34 & Perca fluviatilis Linnaeus, 1758 & - & + & + & Confluenţă/Albie \\
\hline 35 & Sander lucioperca (Linnaeus, 1758) & - & + & + & Confluenţă \\
\hline 36 & $\begin{array}{l}\text { Gymnocephalus cernua (Linnaeus, } \\
\text { 1758) }\end{array}$ & - & + & + & Confluenţă/Albie \\
\hline 37 & $\begin{array}{l}\text { Gymnocephalus acerina (Gmelin, } \\
\text { 1789) }\end{array}$ & - & - & + & Confluenţă \\
\hline 38 & Zingel zingel (Linnaeus, 1766) & - & - & + & Confluenţă \\
\hline 39 & Lepomis gibbosus (Linnaeus, 1758) & - & - & + & Confluenţă/Albie \\
\hline 40 & Babka gymnotrachelus (Kessler, 1857) & + & + & + & Confluenţă/Albie \\
\hline 41 & $\begin{array}{l}\text { Neogobius melanostomus (Pallas, } \\
\text { 1814) }\end{array}$ & - & - & + & Confluenţă \\
\hline 42 & Neogobius fluviatilis (Pallas, 1814) & + & + & + & Confluență/Albie \\
\hline 43 & Ponticola kessleri (Guenther, 1861) & - & - & + & Confluență \\
\hline 44 & $\begin{array}{l}\text { Proterorhinus semilunaris (Heckel, } \\
\text { 1837) }\end{array}$ & + & + & + & Confluenţă/Albie \\
\hline 45 & Benthophilus nudus Berg, 1898 & - & - & + & Confluență \\
\hline \multicolumn{2}{|c|}{ Total } & 20 & 34 & 43 & \\
\hline
\end{tabular}


Diversitatea ihtiofaunistică caracteristică unui râu mic în limitele Republicii Moldova a fost abordată anterior de către autori [1,2], de aceea, în cercetările de faţă se pune accent pe zona de confluenţă - ca zonă de ecoton, având particularităţi deosebite atât structural, cât și funcţional.

Analiza capturilor cu plasa flotabilă în zona de confluenţă (dimensiunile lat. ochiului $40 \mathrm{~mm}, \mathrm{l}=20 \mathrm{~m}, \mathrm{~h}=2 \mathrm{~m}$, distanţa de triere $100 \mathrm{~m}, \mathrm{n}=$ 15 trieri pentru fiecare lună), în diferite luni a perioadei de reproducere, constată cea mai mare valoare a diversităţii specifice în luna mai (15 sp. de pești), după care, cu mic decalaj urmează luna aprilie (13 sp. de pești), luna mai (9 sp. de pești), și cea mai mică diversitate se constată în luna iunie, când nivelul apei scade semnificativ iar sezonul reproductiv s-a finalizat la majoritatea speciilor de pești.

În luna iulie, din cauza precipitațiilor abundente și frecvente ce au cuprins întreaga ţară, s-a constatat majorarea bruscă a nivelului apei în fl. Nistru și r. Răut. În rezultatul acestor viituri de vară structura specifică a capturilor piscicole a crescut din nou (10 sp.) (Tabelul 2).

Valorile maximale a structurii specifice constatate în perioada vernală se datorează viiturilor mari de primăvară și regimului termic ascendent, peștele intrând în masă din fl. Nistru în r. Răut. Printre speciile caracteristice fl. Nistru, dar care activ se ridică în amonte pe Răut menţionăm: cleanul, plătica, taranca/babușca, crapul, scobarul, mreana comună, șalăul, somnul, avatul. Pentru multe specii ihtiofage (șalăul, somnul, știuca, avatul, cleanul, bibanul), ecosistemul r. Răut servește ca sursă importantă de nutriţie cu pești de dimensiuni mici.

În urma viiturilor puternice de la sfârșitul lunii iunie - iulie (a. 2018) s-a constatat migraţia activă pe r. Răut a puietului speciei alogene - sânger, cu vârsta de 2 ani și greutatea corporală cuprinsă între 180-250 g. Având în vedere că populările cu această speciei alogenă nu s-au efectuat în sectorul inferior al fl. Nistru, putem presupune posibilitatea naturalizării sale reușite.

Din tabelul 1 și 2 observăm că majoritatea speciilor de pești ce intră în 
masă în r. Răut în perioada de primăvară fac parte din grupa celor indigene economic valoroase. Astfel, pentru menţinerea productivităţii piscicole înalte de ambele părţi, este vital important de a menţine un regim hidrologic optimal și de a asigura un regim de protecţie strict la nivel de bazin (nu doar pe cursul fluviului).

Analiza indicelor ecologici analitici în capturile cu plasa flotabilă (cu dimensiunile lat. ochiului $40 \mathrm{~mm}$ ) în diferite luni a perioadei reproductive constată următoarele specii dominante (D4) și eudominante (D5) de pești:

- În luna martie: plătica (D5 - 44,19\%), babușca/taranca (D5 - 17,05\%), carasul argintiu (D5 - 13,18 \%) și avatul (D5 - 12,40 \%);

- În luna aprilie: plătica (D5 - 29,75\%), scobarul (D5 - 14,05\%), babușcal taranca (D5 - 10,74\%), carasul argintiu (D5 - 12,40 \%), șalău (D4 - 6,61 \%) și cleanul (D4 - 5,79\%);

- În luna mai: carasul argintiu (D5 - 19,66 \%), plătica (D5 - 12,82\%), babușca/taranca (D5 - 12, 82 \%), scobarul (D5 - 10,26\%), șalăul (D4 7,69\%), batca (D4 - 6,84 \%) și mreana comună (D4 - 5,13\%);

- În luna iunie: carasul argintiu (D5 - 45, 95 \%), babușca/taranca (D5 - 24, $32 \%$ ), plătica (D5 - 10,81\%), batca (D4 - 8,11\%) și soretele (D4 - 5,41\%);

- În luna iulie: plătica (D4 - 7,14\%), cleanul (D4 - 8,04 \%), babușca/taranca (D5 - 20,54\%), carasul argintiu (D5 - 25,89\%), sânger (D5 - 27,68\%) Conform frecvenţei de apariţie în capturi (exprimată prin constanţă) evidenţiem următoarele specii constante (C3) și euconstante (C4):

- În luna martie: plătica (C4 - 86,67\%), babușca/taranca (C4 - 80,00\%), carasul argintiu (C3 - 60,00\%);

- În luna aprilie: plătica (C3 - 66,67\%), carasul argintiu (C3 - 60,00\%), babușca/taranca (C3 - 53,33\%);

- În luna mai: carasul argintiu (C3 - 66,67\%);

- În luna iunie: nu s-au identificat

- În luna iulie: carasul argintiu (C4 - 80,00\%), babușca/taranca (C4 $73,33 \%)$. 


\begin{tabular}{|c|c|c|c|c|c|c|c|c|c|c|c|c|c|c|c|c|c|}
\hline$\frac{\widehat{o}}{3}$ & $\begin{array}{l}2 \\
\alpha \\
0\end{array}$ & 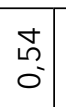 & $\begin{array}{l}\stackrel{0}{ } \\
\stackrel{i}{L}\end{array}$ & $\begin{array}{l}\text { 苞 } \\
0\end{array}$ & $\begin{array}{l}\bar{\lambda} \\
\hat{\mathrm{N}}\end{array}$ & $\begin{array}{l}0 \\
0 \\
0\end{array}$ & 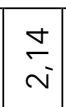 & & $\begin{array}{l}0 \\
m \\
0 \\
0\end{array}$ & & ' & 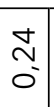 & & 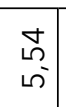 & & . & \multirow{3}{*}{$\begin{array}{l}\frac{\dot{0}}{n} \\
\stackrel{0}{0}\end{array}$} \\
\hline$\frac{\widehat{\Xi}}{u}$ & 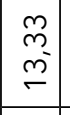 & $\begin{array}{l}8 \\
0 \\
i\end{array}$ & $\stackrel{m}{m}$ & $\begin{array}{l}8 \\
0 \\
i\end{array}$ & $\begin{array}{l}8 \\
0 \\
\infty \\
\infty\end{array}$ & $\begin{array}{l}\hat{0} \\
0 \\
0\end{array}$ & \begin{tabular}{|l|} 
\\
0 \\
0 \\
0 \\
$N$
\end{tabular} & & 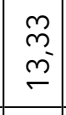 & & ' & $\begin{array}{c}m \\
m \\
m \\
r\end{array}$ & & $\begin{array}{l}8 \\
0 \\
\text { i }\end{array}$ & & ' & \\
\hline 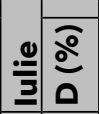 & $\stackrel{\nabla}{\check{N}}$ & $\begin{array}{l}\infty \\
0 \\
\sim \\
\sim\end{array}$ & 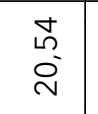 & $\begin{array}{l}\infty \\
0 \\
\sim \\
\sim\end{array}$ & 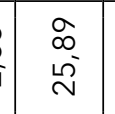 & $\begin{array}{l}0 \\
0 \\
0 \\
0\end{array}$ & $\mid \begin{array}{l}0 \\
0 \\
\infty\end{array}$ & & $\begin{array}{l}\infty \\
0 \\
\stackrel{0}{\sim}\end{array}$ & & . & $\begin{array}{l}\stackrel{a}{=} \\
=\end{array}$ & & 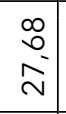 & & , & \\
\hline$\frac{\widehat{\varrho}}{3}$ & $\stackrel{0}{\stackrel{v}{v}}$ & & $\stackrel{\stackrel{m}{m}}{=}$ & $\begin{array}{l}\stackrel{0}{0} \\
\stackrel{0}{0}\end{array}$ & 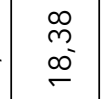 & $\begin{array}{l}0 \\
0 \\
0\end{array}$ & & 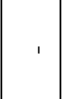 & . & & . & $\begin{array}{l}N \\
\hat{0}\end{array}$ & & , & & ' & \multirow{3}{*}{$\stackrel{0}{n}$} \\
\hline$\frac{\widehat{\varrho}}{\mathfrak{d}}$ & $\begin{array}{l}8 \\
0 \\
0 \\
\end{array}$ & & $\begin{array}{l}1 \\
0 \\
0 \\
0 \\
0\end{array}$ & $\begin{array}{l}\hat{0} \\
0 \\
0\end{array}$ & \begin{tabular}{l}
8 \\
\hdashline \\
$\vdots$ \\
\end{tabular} & $\stackrel{m}{m} \underset{m}{m}$ & & & . & & ' & $\begin{array}{c}\stackrel{m}{m} \\
\stackrel{m}{\longrightarrow}\end{array}$ & & & & , & \\
\hline 害 & \begin{tabular}{|c|} 
\\
0 \\
0 \\
$\circ$ \\
\end{tabular} & & $\begin{array}{c}\stackrel{N}{\infty} \\
\stackrel{\sim}{N}\end{array}$ & $\begin{array}{c}\bar{E} \\
\bar{\infty}\end{array}$ & \begin{tabular}{l}
\multicolumn{2}{c}{} \\
$\alpha$ \\
$\sigma$ \\
$q$
\end{tabular} & $\stackrel{\substack{n \\
\sim}}{\sim}$ & & 1 & . & & , & זٓ & & & & ' & \\
\hline 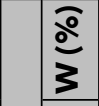 & $\underset{\sim}{\stackrel{\sim}{\sim}}$ & $\stackrel{\mathcal{F}}{=}$ & $\begin{array}{l}\text { d } \\
0 \\
0 \\
0\end{array}$ & 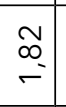 & $\begin{array}{l}\bar{E} \\
\bar{m}\end{array}$ & 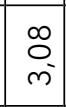 & $\stackrel{\sigma}{=}$ & $\mid \begin{array}{l}n \\
0 \\
i\end{array}$ & $\mid \begin{array}{c}\tilde{m} \\
\tilde{m} \\
0\end{array}$ & $\begin{array}{l}\tilde{n} \\
\tilde{0} \\
\end{array}$ & $\begin{array}{c}\bar{\alpha} \\
\overline{0}\end{array}$ & $\begin{array}{l}2 \\
0 \\
0 \\
0\end{array}$ & 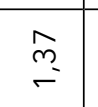 & $\mid \begin{array}{c}\stackrel{3}{\sim} \\
0 \\
0\end{array}$ & $\begin{array}{l}\bar{n} \\
0 \\
0\end{array}$ & ' & \multirow{3}{*}{ 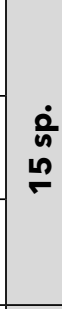 } \\
\hline$\frac{\nwarrow}{\grave{\Xi}}$ & $\begin{array}{c}m \\
m \\
m \\
m\end{array}$ & $\begin{array}{c}m \\
m \\
m \\
m\end{array}$ & 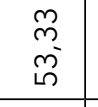 & 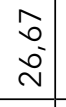 & $\begin{array}{l}10 \\
0 \\
0 \\
0 \\
0\end{array}$ & $\begin{array}{l}8 \\
\vdots \\
0 \\
\end{array}$ & $\begin{array}{l}1 \\
0 \\
0 \\
0 \\
\end{array}$ & $\begin{array}{l}8 \\
0 \\
0 \\
\end{array}$ & \begin{tabular}{|c|}
$m$ \\
$m$ \\
$m$ \\
- \\
\end{tabular} & $\begin{array}{c}m \\
m \\
m \\
\end{array}$ & $\begin{array}{l}0 \\
0 \\
0 \\
0 \\
N\end{array}$ & 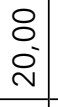 & 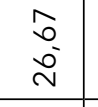 & \begin{tabular}{|l}
$m$ \\
$m$ \\
$m$ \\
$m$
\end{tabular} & $\begin{array}{l}8 \\
0 \\
0 \\
\end{array}$ & . & \\
\hline 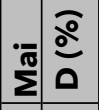 & $\begin{array}{c}1 \\
\infty \\
\stackrel{1}{~} \\
\end{array}$ & 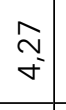 & 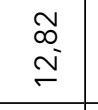 & $\begin{array}{l}\stackrel{1}{\infty} \\
\infty \\
0 \\
\end{array}$ & $\begin{array}{l}\stackrel{0}{\circ} \\
\stackrel{\circ}{\sigma}\end{array}$ & $\begin{array}{l}a \\
0 \\
i \\
\end{array}$ & 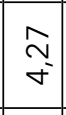 & 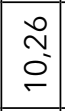 & 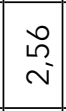 & $\stackrel{\Sigma}{-}$ & $\begin{array}{l}q \\
\tilde{m} \\
\end{array}$ & 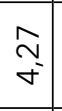 & $\stackrel{m}{i}$ & $\stackrel{\nwarrow}{=}$ & $\begin{array}{l}0 \\
\stackrel{0}{0} \\
\sim \\
\end{array}$ & ' & \\
\hline$\frac{\nwarrow}{3}$ & 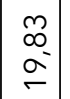 & $\stackrel{\infty}{m} \underset{\sim}{\sim}$ & 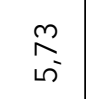 & $\begin{array}{l}0 \\
: \\
0\end{array}$ & $\underset{⿱}{\stackrel{J}{*}}$ & $\begin{array}{l}a \\
a \\
m\end{array}$ & $\begin{array}{l}\stackrel{m}{-} \\
\stackrel{-}{-}\end{array}$ & $\left|\begin{array}{c}\stackrel{n}{1} \\
\stackrel{m}{m}\end{array}\right|$ & 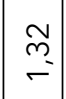 & $\begin{array}{l}0 \\
\stackrel{2}{1} \\
0\end{array}$ & $\begin{array}{l}\approx \\
0 \\
0\end{array}$ & & $\begin{array}{l}\text { 옹 } \\
\text { on }\end{array}$ & & & $\bar{\sigma}_{\sigma}$ & \multirow{3}{*}{$\begin{array}{l}\dot{0} \\
m \\
m\end{array}$} \\
\hline$\frac{\widehat{\varrho}}{u}$ & $\left|\begin{array}{l}0 \\
0 \\
0 \\
0 \\
0\end{array}\right|$ & $\begin{array}{c}m \\
m \\
m \\
m\end{array}$ & 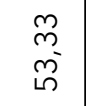 & $\begin{array}{l}8 \\
\circ \\
0 \\
i\end{array}$ & $\begin{array}{l}8 \\
0 \\
0 \\
0\end{array}$ & $\begin{array}{l}\hat{0} \\
0 \\
0 \\
o\end{array}$ & $\mid \begin{array}{l}m \\
m \\
m \\
m\end{array}$ & $\begin{array}{l}1 \\
0 \\
0 \\
0 \\
N\end{array} \mid$ & $\begin{array}{l}1 \\
0 \\
0 \\
0\end{array} \mid$ & $\begin{array}{l}8 \\
0 \\
0 \\
2\end{array} \mid$ & $\mid \begin{array}{c}m \\
\tilde{m} \\
\sim \\
\sim\end{array}$ & & $\begin{array}{l}8 \\
\stackrel{N}{0}\end{array}$ & & & $\begin{array}{l}0 \\
0 \\
0 \\
0\end{array}$ & \\
\hline 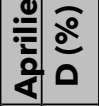 & 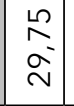 & $\stackrel{m}{\leftarrow}$ & 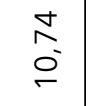 & $\stackrel{\bar{m}}{m}$ & $\begin{array}{l}\stackrel{g}{g} \\
\stackrel{2}{\simeq}\end{array}$ & $\begin{array}{l}- \\
0 \\
0 \\
0\end{array}$ & $\mid \begin{array}{c}2 \\
\hat{n} \\
\llcorner\end{array}$ & $\mid \begin{array}{l}n \\
0 \\
0 \\
-\end{array}$ & $\mid \begin{array}{l}0 \\
2 \\
+\end{array}$ & $\mid \begin{array}{c}\infty \\
\sim \\
\sim\end{array}$ & 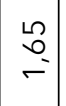 & & $\stackrel{\infty}{\sim}$ & & & $\begin{array}{l}\stackrel{n}{0} \\
\stackrel{0}{=}\end{array}$ & \\
\hline 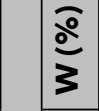 & $\left|\begin{array}{l}a \\
\mathfrak{n} \\
o \\
m\end{array}\right|$ & $\bar{m}_{m}$ & $\begin{array}{l}\text { Jే } \\
\text { m. } \\
\square\end{array}$ & $\overline{\grave{c}}$ & $\stackrel{\bar{a}}{\wedge}$ & $\begin{array}{l}\tilde{0} \\
0 \\
0\end{array}$ & $\mid \begin{array}{l}N \\
\stackrel{2}{0} \\
0\end{array}$ & $\mid$\begin{tabular}{l|}
$n$ \\
0 \\
0 \\
0
\end{tabular} & $\mid \begin{array}{l}\bar{m} \\
\bar{o}\end{array}$ & & , & & & & & ' & \multirow{3}{*}{ ถั่ } \\
\hline$\overline{\frac{o}{0}}$ & $\begin{array}{l}1 \\
0 \\
0 \\
\infty \\
0\end{array}$ & 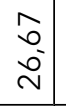 & $\begin{array}{l}8 \\
0 \\
\infty\end{array}$ & $\begin{array}{c}\stackrel{m}{m} \\
\stackrel{m}{r}\end{array}$ & $\begin{array}{l}8 \\
0 \\
0\end{array}$ & $\begin{array}{c}\stackrel{m}{m} \\
m \\
\stackrel{m}{-}\end{array}$ & $\begin{array}{c}m \\
m \\
m \\
m\end{array}$ & $\mid \begin{array}{l}0 \\
0 \\
0 \\
0\end{array}$ & $\begin{array}{l}m \\
m \\
m \\
m\end{array}$ & & , & & & & & , & \\
\hline 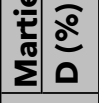 & $\mid \begin{array}{l}a \\
\dot{f} \\
\dot{f}\end{array}$ & $\begin{array}{l}\stackrel{o}{q} \\
\stackrel{1}{\sim}\end{array}$ & $\stackrel{\stackrel{n}{0}}{\stackrel{5}{=}}$ & $\stackrel{\stackrel{\sim}{\stackrel{n}{\circ}}}{\leftarrow}$ & $\stackrel{\infty}{\stackrel{\infty}{\sim}}$ & 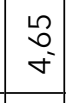 & \begin{tabular}{|l|l}
$\infty$ \\
$\infty$ \\
$m$ \\
$m$
\end{tabular} & $\mid \begin{array}{l}\infty \\
\vdots \\
0\end{array}$ & 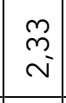 & & . & & & & & 1 & \\
\hline 苟 & 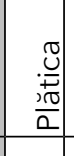 & & 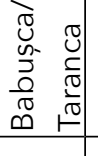 & 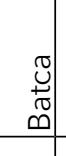 & 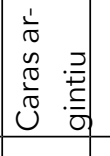 & $\begin{array}{r}\frac{7}{\pi} \\
\frac{2 \pi}{\pi} \\
0\end{array}$ & $\begin{array}{c}\frac{c}{\sigma} \\
\frac{\Phi}{U} \\
U\end{array}$ & 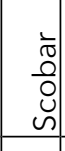 & 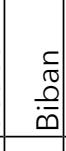 & \begin{tabular}{|l|} 
\\
$\mathbb{0}$ \\
$\mathbb{0}$ \\
0 \\
0 \\
\end{tabular} & 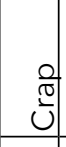 & & 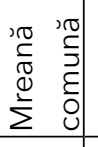 & 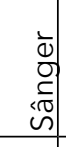 & ही & $\begin{array}{l}\sum^{0} \\
\sum^{0} \\
\Sigma\end{array}$ & \multirow{2}{*}{ 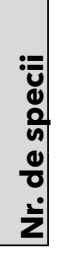 } \\
\hline ż & $\dot{-}$ & & & $\dot{T}$ & & 6 & $r^{\circ}$ & $\infty$ & $\sigma^{\circ}$ & $\stackrel{0}{\circ}$ & 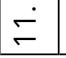 & $\stackrel{\sim}{\check{1}}$ & $\stackrel{m}{=}$ & $\dot{\square}$ & $\stackrel{\dot{\rho}}{\leftarrow}$ & $\stackrel{\circ}{\circ}$ & \\
\hline
\end{tabular}




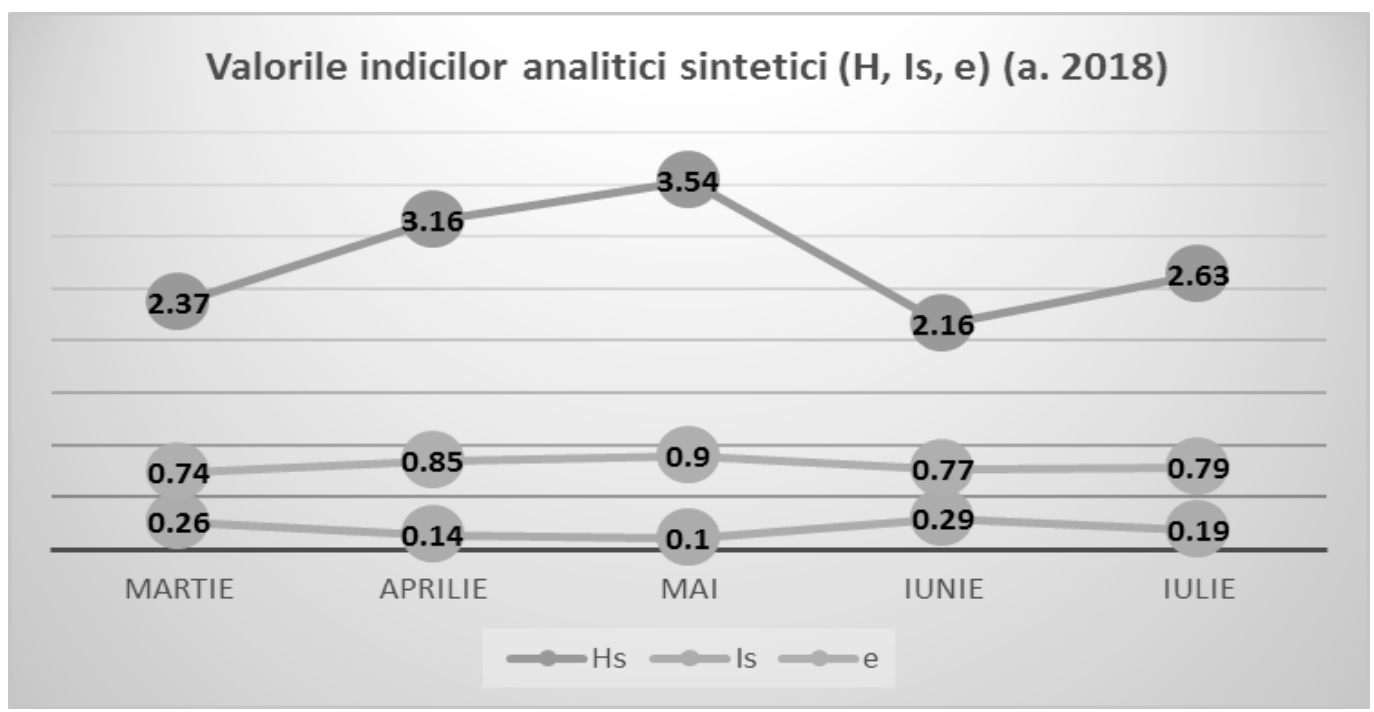

Figura 1 Valorile indicilor ecologici sintetici în capturile piscicole din r. Răut (zona de confluență cu fl. Nistru, 2018).

La analiza indicilor ecologici sintetici constatăm cele mai mari valori a indicelui de diversitate Hs în luna mai $(H s=3,54)$, când structura specifică maximală (15 sp.) are o distribuţie ponderală destul de echitabilă $(e=0,9)$, și cele mai mici valori ale concentraţiei de dominare $(\mid s=0,1)$ (Figura 1).

Cele mai mici valori ale indicelui de diversitate $\mathrm{Hs}(\mathrm{Hs}=2,16)$ se constată în luna iunie, când are loc înrăutăţirea substanţială a regimului hidrologic și termic, iar în structura specifică simplificată crește gradul de dominare a unor reprezentanţi euritopi oportuniști $(\mid s=0,29)$, cum este carasul argintiu (D5 - 45, 95 \%) și babușca/taranca (D5 - 24, 32 \%).

\section{CONCLUZII}

Ihtiofauna r. Răut este constituită din două elemente de bază: 1. specii caracteristice albiei râului cu habitare permanentă (majoritatea cu ciclul vital scurt) și specii caracteristice fl. Nistru și zonei de confluență.

Cea mai mare diversitatea ihtiofaunistică în zona de confluență a r. Răut se constată în perioada de primăvară, când au loc migraţii reproductive și trofice active din fl. Nistru. 
La analiza indicilor ecologici sintetici constatăm cele mai mari valori ale indicelui de diversitate $\mathrm{Hs}$ în luna mai $(\mathrm{Hs}=3,54)$, o distribuţie echitabilă $(e=0,9)$, și cele mai mici valori ale indicelui Simpson $(I s=0,1)$.

Viiturile puternice de vară, servesc ca factori importanţi de demarare a migraţiunilor trofice și reproductive a speciilor de pești din fl. Nistru în r. Răut (sânger, crap, somn, clean, plătica, babușca, carasul argintiu, ș.a.).

Studiul a fost efectuat în cadrul proiectului naţional de cercetări fundamentale 15.817.02.12F și aplicative 15.817.02.27A.

\section{BIBLIOGRAFIE}

1. BULAT DM. Ihtiofauna Republicii Moldova: ameninţări, tendinţe și recomandări de reabilitare. Chișinău: Foxtrod, 2017, 343 p.

2. BULAT DM., BULAT DN., TODERAȘ I., USATîl M., ZUBCOV E., UNGUREANU L. Biodiversitatea, Bioinvazia și Bioidicaţia (în studiul faunei piscicole din Republica Moldova). Chișinău: Foxtrod, 2014, 430 p. ISBN: 978-9975-120-38-8.

3. DAVIDEANU GR. Ghid metodologic pentru monitorizarea structurii ihtiocenozelor, Ed. Performantica, lași, 2013, 57 p.

4. KOTTELAT M., FREYHOF J. Handbook of European Freshwater Fishes. Ed. Delemont. Switzerland. 2007. 646 p.

5. NĂVODARU I. Estimarea stocurilor de pești și pescăriilor. Metode de evaluare și prognoză a resurselor pescărești. Ed. Dobrogea, 2008. p. 46-61.

6. USATîl M. Evoluţia, conservarea și valorificarea durabilă a diversităţii intiofaunei ecosistemelor acvatice ale Republicii Moldova. Autoreferat al tezei de doctor habilitat în știinţe biologice, Chișinău, 2004, 48 p.

7. ПРАВАИН И. РуковоАство по изучению рыб. М., 1966, 400 с 